Sedikides, C., Slabu, L., Lenton, A., \& Thomaes, S. (in press). State authenticity. Current Directions in Psychological Science.

State Authenticity

\author{
Constantine Sedikides ${ }^{1}$ \\ University of Southampton \\ Letitia Slabu \\ Middlesex University \\ Alison Lenton \\ University of Southampton \\ Sander Thomaes \\ Utrecht University
}

We acknowledge support from Economic and Social Research Council grant \#RES-062-232595. Corresponding Author: Constantine Sedikides, Center for Research on Self and Identity, University of Southampton, Southampton, SO17 1BJ; England, UK; Phone: +44 2380594733; Fax: +44 2380594957; Email: cs2@ soton.ac.uk 


\begin{abstract}
State authenticity is the sense that one is currently in alignment with one's true or real self. We discuss state authenticity as seen by independent raters, describe its phenomenology, outline its triggers, consider its well-being and behavioral implications, and sketch out a cross-disciplinary research agenda.
\end{abstract}

Keywords: authenticity, state authenticity, state inauthenticity, well-being 


\section{State Authenticity}

References to authenticity harken back to the Greek philosophers (Harter, 2002), and interest in the concept is contemporaneous to psychology's emergence as a scholarly discipline (Vannini \& Franzese, 2008). Humanists (Maslow, 1971; Rogers, 1961) sowed the seeds for research programs on the authentic person and her/his key characteristics (Kernis \& Goldman, 2006; Wood, Linley, Maltby, Baliousis, \& Joseph, 2008) with their discussions of the "fully functioning person" and "self-actualization." The bulk of the psychological literature since then has focused on (in)authenticity as a trait.

We are concerned with the budding construct of state (in)authenticity. States differ from traits. For one, the former are phenomenologically experienced: "If a person is in a state he or she must be able to feel it" (Fridhandler, 1986, p. 170). More generally, a state is a set of emotions, as well as cognitions and actions, in a particular situation, whereas a trait is an individual's base-rate proclivity toward (or away from) a set of emotions, cognitions, or actions (Fleeson, 2001). Also, states are shorter-lived and manifest continuously in comparison to traits, which are less uniform across time (Fridhandler, 1986).

We start our review by addressing definitional and operational issues. Then we discuss the phenomenology of state authenticity, distinguish it from trait authenticity, consider its triggers, and specify its psychological health implications. We arrive at a counterintuitive conclusion and outline a research agenda.

\section{DEFINING AND OPERATIONALIZING STATE (IN)AUTHENTICITY}

We define state authenticity as the sense or feeling that one is currently in alignment with one's true or genuine self; that one is being their real self. Conversely, we define state inauthenticity as the sense or feeling that one is currently in alignment with an untrue or false self; that one is being a fake self (Lenton, Bruder, Slabu, \& Sedikides, 2013). 
Operationalizations of state (in)authenticity vary. Participants may describe an event during which "you felt most like your true or real self" (state authenticity) and/or an event in which “you felt least like your true or real self” (state inauthenticity; Lenton, Bruder, et al., 2013, p. 280). They may complete the Real-Self Overlap Scale, a single-item pictorial measure of the extent to which they feel close to their true self. Several pairs of circles are shown: In each, the left circle represents "who you are right now" and the right circle represents "your real self (i.e., who you truly are)"; circle overlap escalates from furthestapart to closest-together, and participants select the pair that best represents their current state (Lenton, Slabu, et al.). Participants may complete the state version of the Wood et al. (2008) 12-item authenticity scale (e.g., "right now, I feel out of touch with the real me"; Lenton, Slabu, et al.). They may respond to such items as "I was my true self during the last 20 minutes" and "I felt like I was really being me during the last 20 minutes" (Fleeson \& Wilt, 2010, p. 1361). They may be presented with a list of 60 traits (positive, negative, neutral—in equal numbers) and asked to indicate 10 that describe their true self, or they may be instructed to declare as fast as they can whether their true-self traits are self-descriptive (Schlegel, Hicks, Arndt, \& King, 2009). Finally, participants may respond daily to questions such as "Today I felt that throughout the day I was in touch with my 'true self' and "Today I felt that I wore a number of social masks (reverse-scored)" (Heppner et al., 2008, p. 1141).

\section{THE PHENOMENOLOGY OF STATE (IN)AUTHENTICITY}

State authenticity is a common and familiar experience. Most participants (94\%) report having experienced it relatively frequently (once to twice per week), and most (91\%) also report having experienced state inauthenticity, though far less frequently (every two months). Furthermore, participants assert they are strongly motivated to attain state authenticity and avoid state inauthenticity (Lenton, Bruder, et al., 2013). 
In what situations do people experience state (in)authenticity? Experiences of state authenticity — as judged by independent raters — co-occur with fun, success, returning to familiar people or places, spending time with close others (i.e., hanging out), helping others, and being creative. Conversely, experiences of state inauthenticity—also as judged by raters - co-occur with responding to a difficult situation, being evaluated, being socially incompetent, feeling isolated, conforming to or failing social expectancies, and feeling unwell (Lenton, Bruder, et al., 2013). Thus, state authenticity is experienced in positive or engaging situations in which one feels competent, whereas state inauthenticity is experienced in contexts involving unpleasant challenges where one's standards are salient or at risk of being unmet.

Additionally, raters distinguish experiences of state (in)authenticity on the basis of emotion clusters (Lenton, Bruder, et al., 2013); indeed, Erickson (1995) anticipated these findings when he speculated that emotions are central to the experience of (in)authenticity. Raters perceive state authenticity experiences as higher on satisfaction, relaxation, compassion, pride, and excitement. They perceive state inauthenticity experiences as higher on anxiety, sadness, disappointment, and fear (Lenton, Bruder, et al.). In short, state authenticity is mostly (but not always) characterized by low-arousal positive emotions, whereas state inauthenticity is uniquely characterized by negative emotions (anxiety or lowarousal ones). Moreover, raters deem that state authenticity (vs. inauthenticity) is more likely to result from satisfaction of vital psychological needs (Sheldon, Elliot, \& Kim, 2001): selfesteem, relatedness, autonomy, competence, pleasure, security, meaning, popularity, physical thriving, money. Lastly, raters consider participants who narrated state authenticity (vs. inauthenticity) experiences as having presented a more idealistic self-image, suggesting a closer perceived overlap between the writers' real and ideal selves (Lenton, Bruder, et al.). 
When participants generate and rate their own state (in)authenticity experiences, the results are similar, though not identical. State authenticity entails a return to familiar people or places, hanging out, achievement, creativity, or fun (Lenton, Bruder, et al., 2013). State inauthenticity involves evaluation apprehension, pressure to conform to others' expectations, failing one's own or another's standards, feeling isolated or unwell, or being bereaved (Lenton, Bruder, et al.). Additionally, state authenticity (vs. inauthenticity) is linked to higher positive affect (e.g., excitement, enthusiasm) and lower negative affect (e.g., nervousness, fear; Erickson, 1995). The results of a text analysis program (Linguistics Inquiry and Word Count; Pennebaker, Booth, \& Francis, 2007) further attests to the emotional valence discrepancy between state authenticity and inauthenticity: Experimenter-solicited descriptions of self-confirming experiences (an operationalization of authenticity) contain more positive than negative affect, whereas experimenter-solicited descriptions of selfdiscrepant experiences (an operationalization of inauthenticity) contain more negative than positive affect (Rice \& Pasupathi, 2010). Furthermore, state authenticity (vs. inauthenticity) experiences are associated with greater self-esteem, reduced public and private selfconsciousness, and greater proximity to the ideal self (Lenton, Bruder, et al.). Lastly, state authenticity is believed more likely than state inauthenticity to fulfil (or result from satisfaction of) all vital psychological needs, except money (Lenton, Bruder, et al.; see also Lenton, Slabu, \& Sedikides, 2016). Although relatedness (Deci \& Ryan, 2000; Leary, 2003), as well as competence and autonomy (Deci \& Ryan, 2000), are relevant to the experience of authenticity, these are not the only needs that appear to matter.

The above-described findings generally hold when participants are tested via alternative methods, such as day reconstruction (participants evaluating real-life situations that occur the day before; Lenton et al., 2016), experience-sampling (participants evaluating real-life situations occurring at the moment; Heppner et al., 2008; Lenton et al., 2016), 
experimentation (inducing a true-self [vs. control] mode and assessing whether it enhances perceptions of meaning in life; Schlegel et al., 2009), and latent class analysis (a way to uncover subgroups of individuals with similar reported experiences; Lenton, Slabu, Bruder, \& Sedikides, 2014). Exceptionally, however, the first two methods (day reconstruction and experience-sampling) reveal that state authenticity is associated with an increased rather than decreased acceptance of external influence. Perhaps in many everyday situations, external influence does not necessarily entail pressure to conform to expectations, evaluation apprehension, or failing behavioral standards; instead, it may bring validation and belongingness or indicate value-alignment with the other(s).

Further, the findings generally hold not only in Western cultures (UK, USA), but also in Eastern cultures (China, India, Singapore; Slabu et al., 2014). Though there are some cultural differences in the experience of state (in)authenticity, they are mostly a matter of magnitude than direction. Also, when there are cultural differences, they typically can be understood from relevant cultural norms on self-expression; for example, Germans are seen by fellow Germans as more authentic when they express both likes and dislikes, whereas Chinese are seen by fellow Chinese as more authentic when they express only likes, per each culture's prevailing norm (cultural-fit hypothesis; Kokkoris \& Kühnen, 2014).

\section{STATE AUTHENTICITY AS DISTINCT FROM TRAIT AUTHENTICITY}

State authenticity is distinct from trait authenticity. To begin, state (in)authenticity varies substantially within persons — indeed as much as three times more than between persons (Lenton et al., 2016). For example, participants lowest on trait authenticity may still report state authenticity experiences, and participants highest on it may still report state inauthenticity experiences.

Additionally, the strength of the motivation to attain state authenticity and avoid state inauthenticity is independent of level of trait authenticity, as are the vital psychological needs 
(Sheldon et al., 2001) that state authenticity fulfils (Lenton, Bruder, et al., 2013). Also, having many state authenticity experiences is only weakly associated with having few state inauthenticity experiences $(r=-0.21)$; indeed, $88 \%$ of participants report experiencing both authenticity and inauthenticity at least occasionally (Lenton, Bruder, et al., 2013).

Furthermore, although trait authenticity predicts momentary experiences of authenticity, the correlations are weak: trait authenticity is not merely an aggregate of state authenticity experiences (Lenton et al., 2016). Finally, the phenomenology of state (in)authenticity (i.e., experiences, triggers) is fairly similar across cultures regardless of participants' trait authenticity levels (Lenton et al., 2014; Slabu et al., 2014).

\section{TRIGGERS OF STATE AUTHENTICITY}

State authenticity is triggered by several factors, some intrapersonal, others interpersonal. Intrapersonal triggers include positive mood—induced implicitly or explicitly (Lenton, Slabu, et al., 2013), nostalgia (Baldwin, Biernat, \& Landau, 2016; Stephan, Sedikides, \& Wildschut, 2012), satisfaction of the need for autonomy (Thomaes, Sedikides, Van den Bos, Hutteman, \& Reijntjes, in press), and positivity of a recalled event or behavior (Jongman-Sereno \& Leary, 2016)_-implying that people may believe their authentic self is fundamentally or morally good (Newman, Bloom, \& Knobe, 2014). Interpersonal triggers include interacting with a stranger over the internet - in the relative absence of evaluation apprehension — rather than face-to-face (Bargh, McKenna, \& Fitzsimons, 2002), acting out certain personality traits (e.g., extraversion, agreeableness, conscientiousness; Fleeson \& Wilt, 2010), and sharing one's cherished values (Smallenbroek, Zelenski, \& Whelan, 2017).

\section{WELL-BEING AND BEHAVIORAL IMPLICATIONS OF STATE AUTHENTICITY}

Experiments have shown that state authenticity (vs. state inauthenticity or control) confers psychological benefits. For example, state authenticity enhances subjective vitality (i.e., being alive and energetic) and well-being (Thomaes et al., in press). Also, it elevates 
meaning in life (i.e., purpose and significance of one's life; Schlegel et al., 2009). Moreover, the motivation to attain state authenticity leads to stronger preferences for experiential (e.g., concert tickets) than material (e.g., television set) purchases (Kim, Seto, Christy, \& Hicks, 2016). On the other hand, state inauthenticity engenders subjective immorality and impurity (Gino, Kouchaki, \& Galinsky, 2015), and contributes to unethical or dishonest behavior, such as cheating on various experimental tasks (Gino, Norton, \& Ariely, 2010).

Even indirect experimental manipulation of state authenticity yields psychological benefits. For example, satisfaction of the need for autonomy raises state authenticity, which in turn enhances subjective well-being, operationalized as stronger positive affect and weaker negative affect (Thomaes et al., in press). Furthermore, power (imagining an event in which one had high [vs. low] power), raises state authenticity, which in turn increases subjective well-being (positive and negative affect, satisfaction with life; Kifer, Heller, Qi, Perunovic, \& Galinsky, 2013; Kraus, Chen, \& Keltner, 2011).

\section{CONCLUSION AND RESEARCH AGENDA}

We conclude that state authenticity is a psychologically consequential construct that is distinct from its trait counterpart. Interestingly, it defies the lay intuition that the (working) authentic self is idiosyncratic. State authenticity is predicted from the same types of feelings, thoughts, and behaviors across individuals. That is, its triggers and correlates are universal: It occurs when environmental contingencies are favorable, such as when individuals feel good or competent, when they have positive (Big Five) traits, and when they can express vital psychological needs or values (which are often shared across samples), regardless of trait authenticity level.

The state (in)authenticity research agenda is cross-disciplinary and wide-reaching. First, personality psychology may address the validity of self-perceptions/experiences of state authenticity. When a person feels "most me," is there any accuracy to their claim? To what 
degree is state authenticity "tainted" by self-ideals, that is, who the person aspires to be (Fleeson \& Wilt, 2010; Lenton, Bruder, et al., 2013)? Are some people more likely than others to experience authenticity in the face of adversity? Do cumulative or recurrent experiences of state inauthenticity underlie the imposter phenomenon (i.e., the unfounded fear of being exposed as a fraud, undeserving of one's success; Leary, Patton, Orlando, \& Funk, 2001)? Second, social psychology may enrich inquiry into the triggers of state (in)authenticity. Additionally, it may address the interpersonal nature and functions of state authenticity. These experiences emerge predominantly in social contexts, which raises the possibility that individuals need others, or at least their (real or imagined) presence, to feel true to themselves (Lenton et al., 2014). This would be compatible with the looking-glass self theory holding that one's self is reflected in others (Wallace \& Tice, 2012). Further, can state authenticity backfire in self-presentational settings in which individuals attempt to "be themselves," when instead they should adopt social roles that are more sensitive to situational contingencies (e.g., audience characteristics or expectancies, status differences; Sedikides, Hoorens, \& Dufner, 2015)? Third, I/O or occupational psychology may examine in greater detail the costs of state inauthenticity for employee well-being (e.g., emotional labor; Grandey, Foo, Groth, \& Goodwin, 2012) as well as the potential advantages of state authenticity. Fourth, developmental psychology may investigate systematically the origins and developmental manifestations of state authenticity and state inauthenticity. When are they first experienced (Harter, 2002)? How do they, as well as their triggers and consequences, develop throughout the lifespan? Is state (in)authenticity more typical for some developmental stages than others? Finally, clinical psychology may further examine both the costs and benefits of state authenticity and inauthenticity for psychological functioning (Plasencia, Taylor, \& Alden, 2016). Encouraging facets of state authenticity (Lenton, Slabu, \& Sedikides, 2016) or curtailing facets of state inauthenticity constitute 
viable targets for interventions that seek to ameliorate clinical symptoms. Identifying the answers to questions like the above has the potential to clarify the state authenticity construct and, in particular, specify when and how the sense of real self (valid and not) is experienced, and the circumstances under which it instigates further psychological consequences. 


\section{References}

Bargh, J. A., McKenna, K. Y. A., \& Fitzsimons, G. M. (2002). Can you see the real me? Activation and expression of the "true self" on the internet. Journal of Social Issues, 58, 33-48.

Baldwin, M., Biernat, M., \& Landau, M. J. (2015). Remembering the real me: Nostalgia offers a window to the intrinsic self. Journal of Personality and Social Psychology, 108, 128-147.

Deci, E. L., \& Ryan, R. M. (2000). The "what" and "why" of goal pursuits: Human needs and the self-determination of behavior. Psychological Inquiry, 11, 227-268.

Erickson, R. J. (1995). The importance of authenticity for self and society. Symbolic Interaction, 18, $121-144$

Fleeson, W. (2001). Toward a structure- and process-integrated view of traits as density distributions of states. Journal of Personality and Social Psychology, 80, 1011-1027.

Fleeson, W., \& Wilt, J. (2010). The relevance of Big Five trait content in behavior to subjective authenticity: Do high levels of within person behavioral variability undermine or enable authenticity achievement? Journal of Personality, 78, 1353-1382.

Fridhandler, B. M. (1986). Conceptual, not on state, trait, and the state-trait distinction. Journal of Personality and Social Psychology, 50, 169-174.

Gino, F., Kouchaki, M., \& Galinsky, A. D. (2015). The moral virtue of authenticity: How inauthenticity produces feelings of immorality and impurity. Psychological Science, 26, 983996.

Gino, F., Norton, M. I., \& Ariely, D. (2010). The counterfeit self: The deceptive costs of faking it. Psychological Science, 21, 712-720.

Harter, S. (2002). Authenticity. In C. R. Snyder \& S. J. Lopez (Ed.), Handbook of positive psychology (pp. 382-394). London, UK: Oxford University Press. An early speculation on the development of trait authenticity. 
Heppner, W. L., Kernis, M. H., Nezlek, J. B., Foster, J., Lakey, C. E., \& Goldman, B. M. (2008). Within-person relationships between daily self-esteem, need satisfaction, and authenticity. Psychological Science, 19, 1140-1145.

Grandey, A., Foo, S. C., Groth, M., \& Goodwin, R. E. (2012). Free to be you and me: A climate of authenticity alleviates burnout from emotional labor. Journal of Occupational Health Psychology, 17, 1-14.

Jongman-Sereno, K. P., \& Leary, M. R. (2016). Self-perceived authenticity is contaminated by the valence of one's behavior. Self and Identity, 15, 283-301.

Kernis, M. H., \& Goldman, B. M. (2006). A multicomponent conceptualization of authenticity: Research and theory. Advances in Experimental Psychology, 38, 284-357.

Kifer, Y., Heller, D., Qi, W., Perunovic, E., \& Galinsky, A. D. (2013). The good life of the powerful: The experience of power and authenticity enhances subjective well-being. Psychological Science, 24, 280-288.

Kim, J., Seto, E., Christy, A. G., \& Hicks, J. A. (2016). Investing in the real me: Preference for experiential purchases to material purchases driven by the motivation to search for true selfknowledge. Self and Identity, 15, 727-747.

Kokkoris, M. D., \& Kühnen, U. (2014). "Express the real you”: Cultural differences in the perception of self-expression in authenticity. Journal of Cross-Cultural Psychology, 45, $1221-1228$.

Kraus, M. W., Chen, S., \& Keltner, D. (2011). The power to be me: Power elevates self-concept consistency and authenticity. Journal of Experimental Social Psychology, 47, 974-980.

Leary, M. R. (2003). Interpersonal aspects of optimal self-esteem and the authentic self. Psychological Inquiry, 14, 52-54. 
Leary, M. R., Patton, K. M., Orlando, A. E., \& Funk, W. W. (2001). The impostor phenomenon: Self-perceptions, reflected appraisals, and interpersonal strategies. Journal of Personality, 68, 725-756.

Lenton, A. P., Bruder, M., Slabu, L., \& Sedikides, C. (2013). How does "being real" feel? The experience of state authenticity. Journal of Personality, 81, 276-289.

Lenton, A. P., Slabu, L., Bruder, M., \& Sedikides, C. (2014). Identifying differences in the experience of (in)authenticity: A latent class analysis approach. Frontiers in Psychology: Personality Science and Individual Differences, 5, 1-9.

Lenton, A. P., Slabu, L., \& Sedikides, C. (2016). State authenticity in everyday life. European Journal of Personality, 30, 64-82.

Lenton, A. P., Slabu, L., Sedikides, S., Power, K. (2013). I feel good, therefore I am real: Testing the causal influence of mood on state authenticity. Cognition and Emotion, 27, 1202-1224.

Maslow, A. H. (1971). The farther reaches of human nature. New York, NY: Viking.

Newman, G. E., Bloom, P., \& Knobe, J. (2014).Value judgments and the true self. Personality and Social Psychological Bulletin, 40, 203-216.

Pennebaker, J. W., Booth, R. J., \& Francis, M. E. (2007). Linguistic Inquiry and Word Count (LIWC2007): A text analysis program. Austin, TX: LIWC.

Plasencia, M. L., Taylor, C. T., \& Alden, L. E. (2016). Unmasking one's true self facilitates positive relational outcomes authenticity promotes social approach processes in social anxiety disorder. Clinical Psychological Science, 4, 1002-1014.

Rice, C., \& Pasupathi, M. (2010). Reflecting on self-relevant experiences: Adult age differences. Developmental Psychology, 46, 479-490.

Rogers, C. R. (1961). On becoming a person: A therapist's view of psychotherapy. Boston, MA: Houghton Mifflin. 
Schlegel, R. J., Hicks, J. A., Arndt, J., \& King, L. A. (2009). Thine own self: True self-concept and meaning in life. Journal of Personality and Social Psychology, 96, 473-490.

Sedikides, C., Hoorens, V., \& Dufner, M. (2015). Self-enhancing self-presentation: Interpersonal, relational, and organizational implications. In F. Guay, D. M. McInerney, R. Craven, \& H. W. Marsh (Eds.), Self-concept, motivation and identity: Underpinning success with research and practice. International Advances in Self Research (Vol. 5, pp. 29-55). Charlotte, NC: Information Age Publishing.

Sheldon, K. M., Elliot, A. J., \& Kim Y., (2001). What is satisfying about satisfying events? Testing 10 candidate psychological needs. Journal of Personality and Social Psychology, 80, 325339.

Slabu, L., Lenton, A. P., Sedikides, C., \& Bruder, M. (2014). Trait and state authenticity across cultures. Journal of Cross-Cultural Psychology, 45, 1347-1373.

Smallenbroek, O., Zelenski, J. M., \& Whelan, D. C. (2017). Authenticity as a eudaimonic construct: The relationships among authenticity, values, and valence. The Journal of Positive Psychology, 12, 197-209.

Stephan, E., Sedikides, C., \& Wildschut, T. (2012). Mental travel into the past: Differentiating recollections of nostalgic, ordinary, and positive events. European Journal of Social Psychology, 42, 290-298.

Thomaes, S., Sedikides, C., Van den Bos, N., Hutteman, R., \& Reijntjes, A. (in press). Happy to be "me"? Authenticity, psychological need satisfaction, and subjective well-being in adolescence. Child Development.

Wallace, H. M., \& Tice, D. M. (2012). Reflected appraisal through a 21st-century looking glass. In M. R. Leary \& J. P. Tangney (Eds.), Handbook of self and identity (Vol. 2, pp. 124-140). New York, NY: Guilford. 
Wood, A. M., Linley, P. A., Maltby, J., Baliousis, M., \& Joseph, S. (2008). The authentic personality: A theoretical and empirical conceptualization and the development of the Authenticity Scale. Journal of Counseling Psychology, 55, 385-399.

Vannini, P., \& Franzese, A. (2008). The authenticity of self: Conceptualization, personal experience, and practice. Sociology Compass, 2, 1621-1637. 
Recommended Readings

Harter, S. (2002). Authenticity. In C. R. Snyder \& S. J. Lopez (Ed.), Handbook of positive psychology (pp. 382-394). London, UK: Oxford University Press. An early speculation on the development of trait authenticity.

Heppner, W. L., Kernis, M. H., Nezlek, J. B., Foster, J., Lakey, C. E., \& Goldman, B. M. (2008). Within-person relationships between daily self-esteem, need satisfaction, and authenticity. Psychological Science, 19, 1140-1145. The first state authenticity study employing a diary method.

Kernis, M. H., \& Goldman, B. M. (2006). A multicomponent conceptualization of authenticity: Research and theory. Advances in Experimental Psychology, 38, 284-357. An overview of research on trait authenticity.

Lenton, A. P., Bruder, M., Slabu, L., \& Sedikides, C. (2013). How does "being real” feel? The experience of state authenticity. Journal of Personality, 81, 276-289. The first comprehensive investigation of state authenticity and state inauthenticity.

Wood, A. M., Linley, P. A., Maltby, J., Baliousis, M., \& Joseph, S. (2008). The authentic personality: A theoretical and empirical conceptualization and the development of the Authenticity Scale. Journal of Counseling Psychology, 55, 385-399. An authoritative treatment of trait authenticity, accompanied by a scale. 